Florida International University FIU Digital Commons

6-11-2003

\title{
Development of the Sphere Overlap Scale (SOS) : compartmentalization and the spillover hypothesis
}

Tina Marie Burns

Florida International University

DOI: $10.25148 /$ etd.FI14051887

Follow this and additional works at: https://digitalcommons.fiu.edu/etd

Part of the Psychology Commons

\section{Recommended Citation}

Burns, Tina Marie, "Development of the Sphere Overlap Scale (SOS) : compartmentalization and the spillover hypothesis" (2003). FIU Electronic Theses and Dissertations. 1893.

https://digitalcommons.fiu.edu/etd/1893 
FLORIDA INTERNATIONAL UNIVERSITY

Miami, Florida

DEVELOPMENT OF THE SPHERE OVERLAP SCALE (SOS):

COMPARTMENTALIZATION AND THE SPILLOVER HYPOTHESIS

A thesis submitted in partial fulfillment of the

requirements for the degree of

MASTER OF SCIENCE

in

PSYCHOLOGY

by

Tina Marie Burns

2003 
To: Dean Arthur W. Herriott

College of Arts and Sciences

This thesis, written by Tina Marie Burns, and entitled Development of the Sphere Overlap Scale (SOS): Compartmentalization and the Spillover Hypothesis, having been approved in respect to style and intellectual content, is referred to you for judgment.

We have read this thesis and recommend that it be approved.

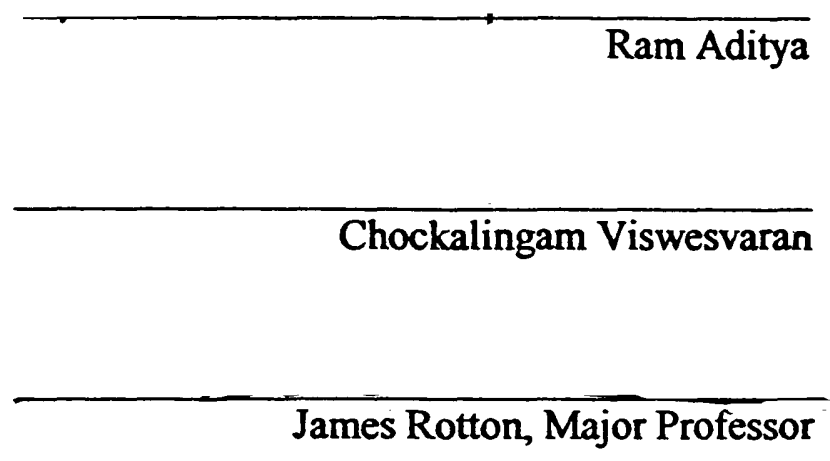

Date of Defense: June 11, 2003

The thesis of Tina Marie Burns is approved.

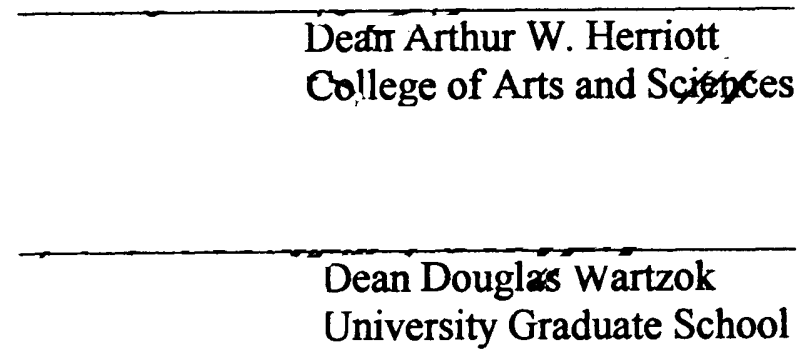

Florida International University, 2003 


\section{DEDICATION}

I dedicate this thesis to my friends, family, and peers. Without their continued support, love, and understanding, this work and the success of my education would not have been possible. In addition, I dedicate this thesis to the memory of my father who remains a constant driving force in my life. 


\section{ACKNOWLEDGMENTS}

I would like to thank my committee members for their time, patience, and willingness to support my work. The knowledge that they have offered has been greatly appreciated. A special acknowledgment goes to my mentor, Professor James Rotton for his continued support and irreplaceable wisdom. 


\begin{abstract}
OF THE THESIS
DEVELOPMENT OF THE SPHERE OVERLAP SCALE (SOS):

COMPARTMENTALIZATION AND THE SPILLOVER HYPOTHESIS
\end{abstract}

by

Tina Marie Burns

Florida International University, 2003

Miami, Florida

Professor James Rotton, Major Professor

The purpose of this study was to create a scale that could measure compartmentalization. In the first of two studies 311 working undergraduates were asked to indicate agreement with 119 items that measured compartmentalization. The resulting scale's reliability and validity were evaluated by having a second sample of 312 working students complete the items that comprise a sphere overlap scale, two measures of spillover, and a measure of personality, coping, and demoralization. Although the study's original goal was not realized, its procedures were successful in developing a short (10-item) measure of work-to-home spillover whose items loaded on a single factor. Structural equation modeling indicated that SOS items were correlated with existing measures of spillover and could be discriminated from related concepts of personality and coping. The SOS was also more highly correlated with demoralization than existing measures of spillover in hierarchical analyses that controlled for demographic factors, personality characteristics, and coping style. It is 
concluded that the SOS shows enough promise to warrant the cost of its appraisal as an alternative measure of spillover in a longitudinal study. 


\section{TABLE OF CONTENTS}

CHAPTER

PAGE

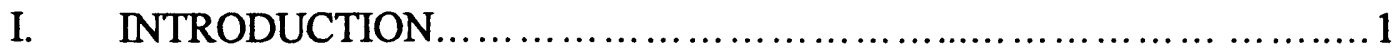

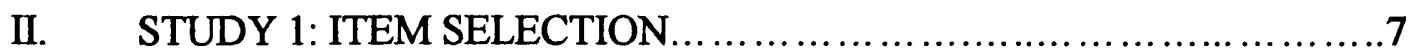

Method............................................................

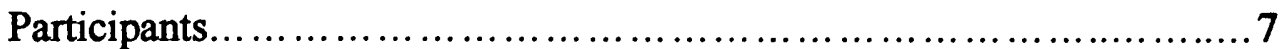

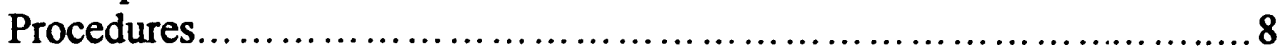

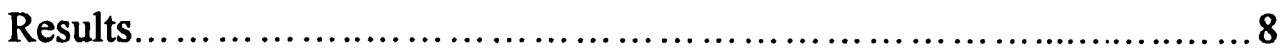

III. STUDY 2: CONSTRUCT VALIDATION ...............................13

Convergent validation.............................................13

Discriminant validity .................................................

Gender and other demographic variables............................15

Moderating effects of compartmentalization............................17

Method............................................................. 18

Participants................................................ 18

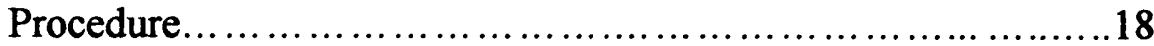

Spillover....................................................

Personality correlates.......................................... 19

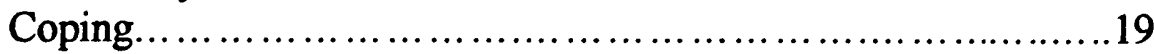

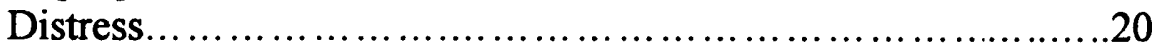

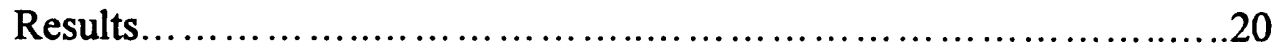

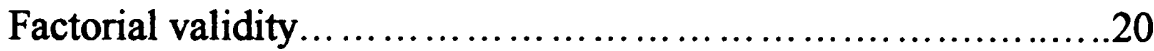

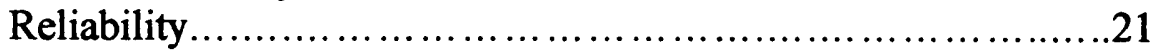

Convergent and discriminant validity ..........................22

Demographic controls....................................23

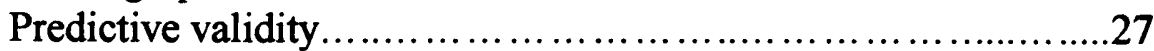

Measurement Models............................................. 27

Confirmatory factor analyses..............................27

Work-home spillover.......................................31

Multidimensional measure of spillover.........................31

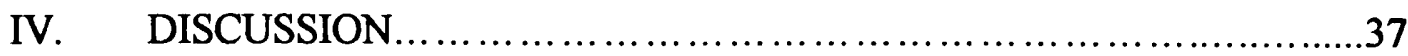

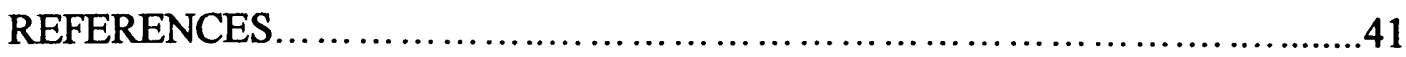




\section{LIST OF TABLES}

TABLE

PAGE

1. SOS 28-item Demographic Data....................................... 11

2. SOS 28-item Correlational Data ............................................

3. Intercorrelations Between Variables...................................... 12

4. SOS 10-item Part-Whole Correlations and Factor Loadings..................21

5. Intercorrelations Between Scales with Alpha Levels.......................25

6. Factor Loadings from Principal-Components Analysis.......................26

7. Summary of Hierarchical Multiple Regression Analysis....................28

8. Standardized Factor Loadings ........................................ 30

9. Factor Loadings for Grzywacz \& Marks (2000) ............................. 33

10. Intercorrelations Among Factors for Grzywacz \& Marks (2000)..............33

11. Factor Scores for Small \& Riley (1990) Scale............................36 


\section{INTRODUCTION}

The home and work place are frequently portrayed as separate spheres that occupy different spaces (home vs. office), involve dissimilar roles (e.g., worker vs. homemaker), and elicit different types of behavior (e.g., work vs. leisure). However, it has long been known that what happens at work spills over to affect an employee's home life (Eckenrode \& Gore, 1990; Frankenhaeuser, 1980; Kabanoff, 1980; Lambert, 1990; Piotrkowki \& Repetti, 1984; Pleck, 1977; Rousseau, 1978; Staines, 1980). For example, Barling and Rosenbaum (1986) found that men in a workshop for abusive husbands reported that they experienced more stress at work than men that were not in the workshop.

Leiter and Durup (1996, p. 30) defined spillover as "a process in which stress in one domain accumulates within a person to be experienced in the other domain." There is ample evidence that stress in the work place spills over to affect family life and behavior at home. Stress in the work place has been linked to marital conflict (Belsky, Perry-Jenkins, \& Crouter, 1985), dissatisfaction of spouses (Small \& Riley, 1990), problem drinking (Bromet, Dew, \& Parkinson, 1990; Greenberg, Moore, \&

Greenberg, 1998), physical and mental health problems (Grzywacz, 2000), physical symptoms (Cooke \& Rousseau, 1984; Small \& Riley, 1990), parenting problems (Small \& Riley, 1990), anxiety (Small \& Riley, 1990), and depression (Barnett, 1994). In addition, as Leiter and Durup's definition suggests, the relationship between stress at work and in the home appears to be reciprocal: Family stress has been found to spill over to affect behavior in the work place (Crouter, 1984; 
Grzywacz \& Marks, 2000; Leiter \& Durup, 1996). However, spillover's effects are not always negative. Positive emotions and experiences at home also spill over to affect behavior at work (Crouter, 1984; Kirchmeyer, 1992) and, vice versa, positive experiences at work affect life at home (Grzywacz \& Marks, 2000).

Attempts to understand spillover are complicated by the fact that the term has also been used to describe what might be termed intra-domain effects. For example, Margolin, Christensen, and John (1996) use "spillover" to explain how the tension between a husband and wife generalizes to impair relationships between parents and children. Spillover has also been used to describe the effects of emotion-provoking events during one period of time on affective states during a later period, regardless of domain or location (Marco \& Suls, 1993; Williams \& Alliger, 1994). The latter, which are sometimes termed "carry-over effects," is not directly relevant to the research that is presented here. This project focused on inter-domain effects, where the work place and home are presumed to be separate, though related spheres of activity. Typically, work and family activities take place in different places and involve different types of activities, although it is recognized that a growing number of individuals earn their living while at home (Ahrentzen, 1989; Ahrentzen, 1990; Farmanfarmaian, 1989; Hartig, Kylin, \& Johansson, in press; Hill, Hawkins, \& Miller, 1996).

Spillover is one of four types of inter-domain effects that Lambert (1990) identified in a seminal review of the literature. The other three are segmentation, compensation, and accommodation. Segmentation describes attempts to separate 
work and family life (Pietrkowski, 1979). Ahrentzen (1989, p. 272) suggested that most workers subscribe to what she termed "the separate sphere ideology." She described this as "the idea that domestic and public life are separate physically and experientially." Staines (1980) proposed that segmentation could also be termed "compartmentalization." Compensation occurs when workers try to find satisfaction in the home sphere because their psychological needs are not met at work: "In general, the theory of compensation views workers as actively seeking greater satisfaction from their work or family life as a result of being dissatisfied with the other" (Lambert, 1990, p. 242). Lambert proposed accommodation as the opposite of compensation. Accommodation is observed when high involvement in one domain leads to low involvement in another. Lambert offered, as examples, what would now be regarded as gender stereotypes: the executive who is so involved in his work that he ignores his family and the working woman who passes up promotions in order to devote more time to her family.

Lambert (1990, p. 244) suggested that spillover, compensation, and segmentation should be regarded as "overlapping, not competing processes." In his view, they "all operate to link work and family" (p. 243). His review cites several investigations (Belsky, Perry-Jenkins \& Crouter, 1985; Campbell, Converse \& Rodger, 1976; Crouter, 1984; Piotrkowski, 1979) that found evidence for both spillover and compensation. However, two arguments can be made for regarding segmentation and spillover as complimentary rather than overlapping processes. First, it can be argued that individuals engage in segmentation (i.e., 
compartmentalize) as a way of avoiding or reducing spillover; that is, the more that individuals worry about problems at work affecting their home life, the more likely they will try to keep the two spheres separate. This study explored the possibility that individuals engage in compartmentalization as a way of coping with stressors that they encounter at work, home, or both. The possibility of a buffering effect was suggested by interviews that Weiss (1990) conducted. Although Weiss's findings are anecdotal, they indicate that many husbands refrain from telling their wives about the problems they encounter at work. Second, if compartmentalization is an effective coping mechanism-that is, if its use does in fact reduce spillover-then there should be a negative correlation between measures of spillover and the overlap between work and home domain.

The present study was designed to develop and validate a scale to assess overlap between work and non-work (family, home, and leisure) spheres of activity. More specifically, the aim was to create an overlap scale that would be able to measure the construct of compartmentalization, which can be defined as a coping mechanism that enables individuals to reduce and avoid the stress that is (or might be) caused by events from one sphere spilling over to affect thoughts, feelings, and activities in another sphere. This is, of course, a conceptual definition; the goal was to develop a scale that could be used to assess this way of coping with spillover at the boundary of home and the workplace. This study's conceptual definition is similar to Eckenrode and Gore's (1990, p. 4) "boundary maintenance," which they defined as "activities initiated by family members or persons in the workplace (at the 
individual or organizational level) designed to foster or maintain a given type of boundary between those roles." As examples, Eckenrode and Gore observed that corporations sometimes discourage personal phone calls, and a worker may have unlisted phone numbers in order to avoid getting work-related calls at home.

This study's definition of compartmentalization is considerably broader than prior uses of the word. For example, Showers and Kling (1996; Showers \& Ryff 1996) used the word to describe attempts to separate positive and negative thoughts about one's self. It is also broader than the one found in articles and chapters on role theory (Sarbin \& Allen, 1968; Turner, 1978). Given role theory's origins in drama, it is perhaps not surprising that role theorists have focused on how individuals use compartmentalization when they present themselves to others; for example, as Goffman (1959) observed, it is not unusual for teenagers to swear when they are with their peers but refrain from doing so when they are talking with their parents. In the same way, if one excludes telecommuters, workers compartmentalize by engaging in different activities while at home and in the work place (i.e., work vs. leisure). However, this study's conceptual definition includes thoughts and feelings as well as observable activities; that is, going beyond what people do (i.e., observable activity), it was proposed that workers also compartmentalize when they put events at home out of their minds when they have to accomplish tasks at work and, conversely, they try to "leave the office behind" when they return to their homes.

Lest the reader is misled and subsequently disappointed, I feel obliged to report that the main purpose of this study (to create a measure of 
compartmentalization), was not attained. Thus it was possible to test only one of the two hypotheses that were originally formulated: An individual's level of strain is positively related to their level of spillover. The study's other hypothesis could not be tested: Compartmentalization has a buffering effect on the relationship between spillover and strain. Instead of creating a scale of compartmentalization the study was successful in creating a new instrument for assessing negative work-to-home spillover that appears to be more valid than existing measures: the Sphere Overlap Scale (SOS).

The first study describes procedures that were followed in an effort to construct the SOS. Its goal was to develop a relatively short (28-item) Likert-type scale that would assess cognitive and behavioral efforts (i.e., compartmentalization) for avoiding and reducing overlap between home and work spheres. The second study had validation as its main focus. Its dual aims were to assess the validity of compartmentalization as a construct and, simultaneously, the SOS as a measure of that construct. This was attempted by performing an exploratory factor analysis on the responses from an employed group of participants and by examining correlations between scores on the SOS and several measures of personality, coping, and psychological strain. In other words, the second study had convergent and discriminant validation as its goal. 


\section{STUDY 1. ITEM SELECTION}

\section{Method}

Three subject matter experts (a faculty member and two graduate students in psychology) wrote 119 items that were believed to capture the concept of compartmentalization and its opposite, overlap between work and home spheres. ${ }^{1}$ The following was employed as exemplar of compartmentalization and was used as a criterion (marker) when selecting the final 28 items that comprised the Sphere Overlap Scale (SOS): "I try to keep my life at home and at work separate and apart from each other." Twenty-nine items were phrased so that agreement was indicative of compartmentalization (e.g., "I have a different set of friends at home and at work"); another 90 items were phrased so that agreement was indicative of spillover or overlap between the spheres of home and work (e.g., "I check my office email when I am home"). Response alternatives for the items were "strongly agree," “agree", "neither agree nor disagree," "disagree," and "strongly disagree".

Participants. The sample was comprised of $314($ male $=118$, female $=196)$ undergraduate and graduate (Psychology, Business, and Education majors) students who indicated that they were employed either full or part-time while attending classes at Florida International University. Participants were recruited from classes whose instructors had established procedures for encouraging participation in psychological experiments.

${ }^{1}$ I would like to acknowledge the assistance of Stephen M. White who collaborated in writing the original 50 items that were included in the final pool. 
Procedures. Informed consent was obtained from each participant.

Participants were then asked to complete a three-part questionnaire. The first part of the questionnaire contained items for obtaining demographic information about gender (male vs. female), age, ethnicity (Black/African-American, Hispanic, Anglo, Asian, Other), total family income (under $\$ 15,000 ; \$ 15,001-29,999 ; \$ 30,000$ $\$ 44,999 ; \$ 45,000-59,999 ; \$ 60,000$ and over), and employment status (employed 40 hours or more a week; less than 40 hours; not currently employed; never employed). The last item was a check to make sure that only employed individuals were included in the analyses. The second part contained the 119 items that were candidates for inclusion on the SOS. The third part was composed of the 33 items that comprise Crowne and Marlowe's (1960) Social Desirability Scale. A sample item from that scale is "I am sometimes irritated by people who ask favors of me." The scale's response format is "true" or "false." Robinson, Shaver and Wrightsman (1991) reported that alpha coefficients for the social desirability scale ranged from .73 and .88 in prior investigations. Following completion of the scale, participants were provided with feedback in the form of a sheet that described the purpose of the study, and any questions that individuals may have had were answered at that time. $\underline{\text { Results }}$

Item analysis. The outcome of the first study resulted in the construction of a refined 28-item Sphere Overlap Scale (SOS), which had a coefficient alpha of .79. This scale was constructed by using Nunnally and Bernstein's (1994) discrimination 
indices (i.e., item-total correlations, p-values, alpha, $\&$ distribution) as well as a nontraditional procedure.

The items were rank ordered according to their corrected item-total $r$. The criterion for including an item was then set at $\underline{r} \geq .3$ (Nunnally \& Bernstein, 1994, p. 305). This criterion resulted in the selection of 15 items. Additional items were then selected using other discrimination indices such as alpha and p-values. This step resulted in the addition of 12 more items to the scale (Nunnally \& Bernstein, p. 306). . Finally, since the marker item was still unable to meet any of the prior criteria, it was included in the final 28 items based on the original goal of this study (to create a measure of compartmentalization). The original idea for the marker item was to establish a criterion for the SOS scale that all other items would be assessed on. However, since none of the items from the original pool significantly related to the marker item, the marker as a criterion for the item selection procedures was changed to processes recommended by Nunnally $\&$ Bernstein.

Table 1 reports the means and standard deviations for items on the 28 -item version of the SOS. Note that the sample size was reduced to 311 because 3 respondents neglected to answer a small (two or fewer) number of items. Table 2 reports the part-whole item correlations, with the Marlow-Crowne Social Desirability scale, and t-values for gender comparisons. The SOS had item partwhole correlations that ranged from .15 to .47 . The item part-whole correlations controlled for each items overlap with the sum of the remaining 27 SOS items. There were no positive (and only a few negative) correlations found between the SOS 
items and the social desirability scale; thus no items were removed because of social desirability. However, the SOS total score was negatively correlated with the total score of social desirability $(\underline{r}=-.19, \underline{p}<.05)$. Because this was a relatively low correlation social desirability was judged not to be a threat to the SOS scale. Gender differences were statistically significant $(p<.05)$ for 5 SOS items (item number's 3 , $5,20,24,25)$, but not for total scores, $\underline{\mathrm{t}}(309)=.41, \underline{\mathrm{p}}>.05$.

The scale's generality was assessed by examining correlations with demographic items (i.e., age and income) and by comparing the scores of male and female employees. Intercorrelations for the 28-item SOS, social desirability scale, and demographic items of gender (scored 1,0), and age are reported in Table 3. Results indicate that age is significantly related $(\underline{r}=.20, \underline{p}<.01)$ to income and employment status $(\underline{r}=-.27, \underline{p}<.01)$, but there were no significant relations found between the SOS and any of the demographic variables. 
Descriptive Statistics for the Sphere Overlap Scale (Study 1)

\begin{tabular}{|c|c|c|}
\hline Items & $\underline{\mathrm{M}}$ & $\underline{\mathrm{SD}}$ \\
\hline $\begin{array}{l}\text { 1. I try to keep my life at home and at work separate and apart from } \\
\text { each other. }{ }^{\mathrm{a}} \text { (marker item) }\end{array}$ & $\overline{3.14}$ & $\overline{1.34}$ \\
\hline $\begin{array}{l}\text { 2. When I get into a dispute with coworkers I dwell on the problem } \\
\text { when I am at home. }\end{array}$ & 2.75 & 1.33 \\
\hline 3. I think about problems at work when I am on vacation. & 2.01 & 1.32 \\
\hline $\begin{array}{l}\text { 4. I hardly ever encounter coworkers when I leave my job and return } \\
\text { to my home and neighborhood. }\end{array}$ & 2.99 & 1.53 \\
\hline 5. I bring my work home with me. & 2.26 & 1.36 \\
\hline 6. When someone at work criticizes me for something, I dwell on it & 2.84 & 1.35 \\
\hline
\end{tabular}
at home.

7. If someone insults me at work, I still feel on the offensive when I $\quad \begin{array}{lll}2.65 & 1.28\end{array}$ arrive home.

8. I have a different set of friends at work and at home. ${ }^{\mathrm{a}} \quad 3.05 \quad 1.47$

9. I check office email when I am at home. $\quad 2.09 \quad 1.30$

10. I find myself thinking about people from work while I am at home. $\begin{array}{rr}2.46 & 1.26\end{array}$

11. My boss has never met my spouse. ${ }^{a} \quad \begin{array}{lll}2.60 & 1.50\end{array}$

12. I hardly run into people from my neighborhood when I am at work. ${ }^{a} \quad 3.30 \quad 1.40$

13. When two co-workers are in an argument, I worry about it both day $2.24 \quad 1.16$ and night.

14. I discuss family problems with my boss.

$2.12 \quad 1.26$

15. I have hobbies that keep me from thinking about work when I'm at $\quad \begin{array}{ll}2.40 & 1.26\end{array}$ home. $^{\mathrm{a}}$

16. If I argue with a co-worker, I can't get it off my mind all night. $\quad \begin{array}{lll}2.99 & 1.44\end{array}$

17. An argument with my co-workers often ruins my whole day. $\quad \begin{array}{lll}2.45 & 1.33\end{array}$

18. I spend part of the weekend planning for the next week's work. $\quad \begin{array}{lll}2.49 & 1.46\end{array}$

19. I send work related e-mail messages from home. $\quad 1.99 \quad 1.18$

$\begin{array}{lll}\text { 20. At dinner, work often comes up in conversation. } & 2.93 & 1.37\end{array}$

21. I take my frustrations with my boss, home with me whether I want $\begin{array}{lll}2.36 & 1.30\end{array}$ to or not.

22. I think about my co-workers while driving to work. $\quad \begin{array}{lll}2.57 & 1.31\end{array}$

23. I rarely talk about work when I am at home. ${ }^{a} \quad \begin{array}{lll}2.80 & 1.37\end{array}$

24. I take my frustrations from work home with me whether I want to $\begin{array}{rl}2.49 & 1.25\end{array}$ or not.

25. My friends and I frequently discuss work-related problems. $\quad \begin{array}{lll}2.99 & 1.29\end{array}$

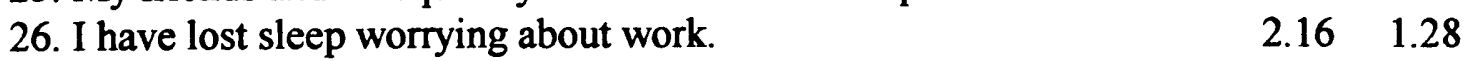

27. I think about my boss while driving to work. $\quad \begin{array}{lll}2.40 & 1.39\end{array}$

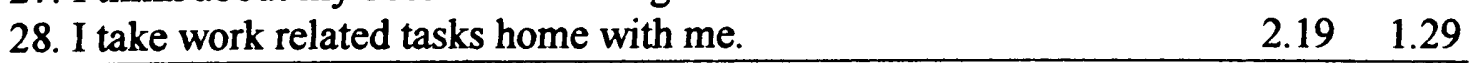

$\mathrm{a}=$ reverse scored items.

${ }^{*} \mathrm{p}<.05 .{ }^{* *} \mathrm{p}<.01$ 
Table 2

SOS 28-item Correlations $(n=311, \alpha=.79)$

\begin{tabular}{|c|c|c|c|}
\hline Items & $\begin{array}{l}\text { Part-whole } \\
\text { Correlations } \\
\end{array}$ & $\begin{array}{l}\text { Correlations between } \\
\text { each SOS item \& MC }\end{array}$ & $\begin{array}{l}\mathrm{t} \text { values } \\
\text { male }>\text { female }\end{array}$ \\
\hline $1^{*}$ (marker) & .18 & .00 & 1.59 \\
\hline 2 & .23 & -.08 & .97 \\
\hline 3 & .38 & -.06 & $2.03 *$ \\
\hline 4 & .24 & -.06 & .68 \\
\hline 5 & .34 & .04 & $2.18^{*}$ \\
\hline 6 & .26 & -.22 & 1.24 \\
\hline 7 & .18 & -.08 & .61 \\
\hline $8^{*}$ & .15 & $-.20^{* *}$ & 1.22 \\
\hline 9 & .40 & -.01 & .05 \\
\hline 10 & .36 & -.08 & .68 \\
\hline $11^{*}$ & .17 & -.02 & .55 \\
\hline $12^{2}$ & .22 & -.09 & .13 \\
\hline 13 & .31 & .02 & .19 \\
\hline 14 & .25 & .03 & .49 \\
\hline $15^{*}$ & .25 & $-.14 * *$ & .01 \\
\hline 16 & .42 & .02 & 1.01 \\
\hline 17 & .25 & $-.13^{*}$ & 1.66 \\
\hline 18 & .23 & .07 & .81 \\
\hline 19 & .40 & .06 & 1.33 \\
\hline 20 & .41 & -.02 & $2.06^{*}$ \\
\hline 21 & .40 & $-.18 * *$ & 1.16 \\
\hline 22 & .39 & -.10 & 1.77 \\
\hline $23^{*}$ & .20 & .08 & 1.37 \\
\hline 24 & .42 & $-.22 * *$ & $2.21^{*}$ \\
\hline 25 & .32 & .00 & $2.04^{*}$ \\
\hline 26 & .40 & -.06 & 1.89 \\
\hline 27 & .40 & $-.12^{* *}$ & .57 \\
\hline 28 & .47 & -.01 & .10 \\
\hline
\end{tabular}

$a=$ reverse scored items. Part-whole correlations partial out the item that is being correlated from the overall scale score. Male $=1$,

Female $=2$.

${ }^{*} \mathrm{p}<.05 . \quad{ }^{* *} \mathrm{p}<.01$

Table 3

Intercorrelations Between Variables $(\mathrm{n}=311)$

\begin{tabular}{|c|c|c|c|c|c|c|c|c|}
\hline Variable & $\underline{\mathrm{SD}}$ & $\underline{\mathrm{M}}$ & 1 & 2 & 3 & 4 & 5 & 6 \\
\hline 1. Gender & 1.63 & .48 & - & & & & & \\
\hline 2. Age & 26.13 & 6.98 & -.03 & -- & & & & \\
\hline 3. Income & 3.36 & 1.26 & .03 & $.20 * *$ & -- & & & \\
\hline 4. Employ status & 1.55 & .51 & .01 & $-.27^{* *}$ & -.07 & -- & & \\
\hline 5. Social desirability & 14.72 & 4.60 & $.13^{*}$ & -.01 & -.01 & -.09 & -- & \\
\hline 6. SOS & 2.64 & .40 & -.02 & .14 & -.03 & -.02 & $-.19 * *$ & -- \\
\hline
\end{tabular}




\section{STUDY 2. CONSTRUCT VALIDATION}

A second, more ambitious study was undertaken to assess the reliability and construct validity of the SOS. This was accomplished by having a second group of employed students complete a questionnaire that contained the SOS and measures of spillover, coping strategies, personality traits, and psychological strain.

\section{Convergent Validation}

Convergent validity was evaluated by determining if scores on the SOS were correlated with two measures of spillover. One of the measures was the worker version of Small and Riley's (1990) Work Spillover Scale. This is a 20-item inventory that assesses the extent to which work spills over to affect marital relationships (e.g., "My job keeps me from spending time with my spouse"), leisure (e.g., "My job makes it difficult for me to enjoy my free time outside of work"), and home management (e.g., "I spend so much time working that I am unable to get much done at home"). The word "spouse" was changed to "significant other" for the purpose of this study. It was anticipated that each type of spillover would be correlated with sphere overlap. The other spillover measure was a 16-item scale that was developed by Grzwacz and Marks (2000) to assess both negative and positive spillover from work to family and from family to work. Four items assessed negative consequences of a work-to-home spillover (e.g., "Your job makes you feel too tired to do things that need attention at home"), another four assessed positive consequences of work-to-home spillover (e.g., "The things you do at work help you deal with personal and practical issues at home"), four more assessed negative 
consequences of home-to-work spillover (e.g., "Personal or family worries and problems distract you when you are working"), and a final four assessed positive consequences of home-to-work spillover (e.g., "The love and respect you get at home makes you feel confident about yourself at work").

\section{Discriminant Validity}

Compartmentalization was conceptualized as a coping mechanism that enables individuals to minimize the strain associated with home-to-work and workto-home spillover. Other types of coping were assessed by Edwards and Baglioni's (1993) Cybernetic Coping Scale. This 20-item scale is based on Edwards' (1992) theory of stress, coping, and well being in organizations.

It can be argued that compartmentalization is a form of avoidance coping. Indeed, there are some (Roth \& Cohen, 1986) who have proposed that everything a person does is a form of either approach or avoidance coping. However, it was hypothesized that the SOS measures behaviors that are distinct from avoidance and other types of coping. Two types of analyses were performed to test this hypothesis and, in the process, demonstrate the scale's discriminant validity. One was a test comparing compartmentalization's correlation with the measures of spillover and the five types of coping. It was anticipated that compartmentalization's correlation with the average of the spillover measures would be significantly higher than its correlation with the average of coping measures. The other was a factor analysis of all of the measures used in the study. 
Coping is usually regarded as situation-specific, whereas compartmentalization encompasses behaviors that characterize behavior in the broad spheres of home and work; therefore, it was anticipated that a factor analysis would reveal that individuals who compartmentalize at work also use compartmentalization at home to deal with stress. This raises the possibility that compartmentalization is a trait rather than a way of coping with stress. Allport and Obert (1936, p. 171) defined traits as "consistent and stable modes of an individual's adjustment to his environment." This presents an almost insurmountable obstacle, because there is already a very large number of personality inventories available to theorists and researchers; as John and Srivastava (1999, p. 102) observed, "the number of personality traits, and scales designed to measure them, has escalated without an end in sight." Nevertheless, there is a considerable amount of evidence that most traits can be subsumed under what has been termed "the Big Five" (i.e., extraversion, agreeableness, conscientiousness, neuroticism, and openness/intellect). Respondents in this study were asked to complete a relatively short but reliable and generally accepted measure of these five traits (John, Donahue, \& Kantle, 1991). Once again, it was anticipated that correlations with scores on the SOS would be less than correlations between the SOS and scales used to assess spillover.

\section{Gender and Other Demographic Variables}

The spillover hypothesis is inextricably linked to early research (Crouter, 1984; Grzywacz \& Marks, 2000; Pleck, 1977) that suggested women are more likely to experience work-job interference than men. For example, Eckenrode and Gore 
(1990) observed that a man's only job was to earn a living, whereas employed women were expected to do household chores as well as work outside the home. It has been mothers because they also received phone calls about their children while they were working. Although these suggestions are consistent with widely held stereotypes, mixed results have been obtained in studies that have examined gender. On the one hand, Piotrkowski and Repetti (1984) found that women had stronger home-to-work spillover. On the other hand, Bolger, Delongis, Kessler and Wethington (1989) found that home-to-work spillover was significantly stronger for men than women. It may be that spillover was once a more serious problem for women than it was for men, but more recent studies have failed to uncover reliable sex differences (Chan \& Margolin, 1994; Gryzwacz \& Marks, 2000). There are even studies (e.g., Larson, Richards, \& Perry-Jenkins, 1994) which have found that working mothers report more positive states when they are in the workplace. This result is consistent with Barnett and Hyde's (2001) expansionist theory, which suggests that women benefit from occupying multiple roles.

The literature in this area contained too many inconsistencies to justify formulating hypotheses about how men and women might differ in their responses to the questionnaires included in this study. However, speculation about sex differences suggested several variables that needed to be examined as potential confounds. Two of the most obvious are marital and parental status. It would not be surprising to find that married individuals and parents are more likely than single persons and individuals without children to resort to compartmentalization as a way of coping 
with the demands of multiple roles. Another potential confound was the number of hours an individual works outside the home (Gryzwacz \& Marks, 2000).

The Moderating Effects of Compartmentalization

The study's original purpose was to determine if compartmentalization acts as a buffer that reduces and perhaps even counteracts adverse effects associated with spillover. It was hypothesized that workers who scored low on this study's measure of compartmentalization would show more signs of strain when they had to contend with spillover, but those who scored high would not show any more signs when spillover is high than when it is low. It was originally planned that this buffering hypothesis would be tested by including a measure of demoralization as a criterion measure. Demoralization has been described as a mild (i.e., non-clinical) level of depression (Dohrenwend, Dohrenwend, Oksenberg, Cook, \& Shrout, 1974).

Demoralization is a more general outcome than ones examined in past studies on spillover, which have employed separate measures of depression, anxiety, and physical health (Geller \& Hobfoll, 1994; Netemeyer, Boles \& McMurrian, 1996; Spence \& Robbins, 1992). However, the Demoralization Scale used here includes items that reflect mild levels of anxiety and physical symptoms as well as depression (Dohrenwend, Dohrenwend, Fabrikant, Kasl, \& Warheit, 1979). The scale has been used, in past research, to detect the effects of air pollution (Evans, Jacobs, Dooley \& Catalano, 1987), technological catastrophes (Kasl, Chisholm, \& Eskenazi, 1981), and muscular spasms (Lennon, Dohrenwend, Zautra, \& Marbach, 1990). 
Method

Participants. The second study's sample consisted of 312 (99 male; 213 female) undergraduate and graduate students attending Florida International University who, as in the first study, indicated that they were employed (139 fulltime; 173 part-time $)$. The sample's age ranged from 18 to $58(\underline{\mathrm{M}}=24.95, \underline{\mathrm{SD}}=$ 6.29). It was composed of 111 Anglos, 124 Hispanics, 59 African Americans, 3 Native Americans, and 15 Asian Americans. Of the 312 participants, 230 were never married, 13 were divorced or widowed, and 69 were married or living together. A total of 58 participants reported having children, and 254 reported no children. A separate sample of 50 (16 male; 34 female) participants was asked to complete the SOS twice, with a six-week interval between assessments, in order to assess the scales test-retest reliability.

Procedure. Participants were asked to complete a questionnaire composed of the 28 SOS items selected from Study 1, demographic items, two measures of spillover, an inventory that assesses the five personality traits, and the demoralization scale. They were assured that their responses would be anonymous. Those who returned the questionnaire were offered feedback, and the author or a representative answered any questions they may have had.

Spillover. One of the questionnaires was Small and Riley's (1990) Spillover Scale for Workers. Small and Riley reported an alpha coefficient of .93 for their 20item scale. They reported that the alpha coefficients for its four subscales range from .79 (for household spillover) to .83 (for marriage spillover). Respondents were asked 
to answer items on this inventory on a 5-point scale that ranged from "strongly disagree" (1) to "strongly agree" (5). The other spillover measure was the 16-item scale developed by Grzywacz and Marks (2000), which was answered on scales whose alternatives range from "never" (1) to "all of the time" (5). Grzywacz and Marks reported the following reliability coefficients for four subscales: For negative spillover from work to home, alpha $=.83$; for positive spillover from home to work, alpha $=.80$; for positive spillover from work to home, alpha $=.73$; and for positive spillover from home to work, alpha $=.70$

Personality Correlates. John, Donahue, and Kantle (1991) reported that their Big Five Inventory has an alpha coefficient of .88 for extraversion, .79 for agreeableness, .82 for conscientiousness, .84 for neuroticism, and .81 for openness. Correlations between these scales and the NEO Inventory (Costa \& McCrae, 1989) range from .64 for openness to .79 for conscientiousness (John \& Srivastava, 1999).

Coping. Edwards and Baglioni's (1993) Cybernetic Coping Scale measures five types of coping: accommodation (e.g., "I made an effort to change my expectations"), devaluation (e.g., "I told myself the problem was unimportant"), symptom reduction (e.g., "I just tried to relax"), avoidance (e.g., "I refused to think about the problem"), and changing the situation (e.g., "I tried to change the situation to get what I wanted"). Respondents were asked how they cope with problems associated with what might be an ideal job. Responses are scored on a 5-point scale that range from "did not use at all"(1) to "used very much" (5). The 5-point scale is an adjustment to the original 7-point scale due to recording form restrictions. 
Edwards and Baglioni report that the 7-point response format on their scales had reliabilities (i.e., alpha coefficients), which range from .66 to .93 for the five types of coping.

Distress. Dohrenwend et al.'s (1979) Demoralization Scale is a 25-item inventory that includes items indicative of depressed affect, anxiety, and physical symptoms (e.g., "During the past two months have you wondered if anything was worthwhile anymore?"). Response alternatives are "never," "sometimes," and "often". Dorhrenwend and colleagues reported that the scale has an alpha coefficient level of .90 .

$\underline{\text { Results }}$

Factorial Validity. A principal components factor analysis followed by a varimax rotation was performed in order to obtain factor loadings for the newly created SOS scale. The SOS was found to load on eight factors. Because this number was judged to be excessive, the SOS was further refined by using methods suggested by Nunnally and Bernstein (1994). Item selection procedures (deletion of any item with a corrected item-total $\underline{r} \geq .3)$ were used until a significant alpha level (.80) was attained. Next, the items derived from the item selection process were entered into a principal components factor analysis. This analysis was followed by the deletion of any item on factors with eigenvalues less than one. These procedures generated a 10item scale that loaded on one factor.

Table 4 reports the part-whole correlations as well as factor loadings for the 10-item SOS. Scores on this scale were significantly correlated with the original 28- 
Table 4

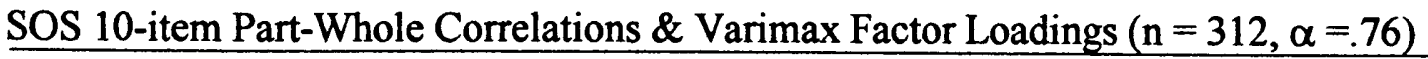

Part-whole Factor

$\begin{array}{ll}\text { Items } & \text { Correlations Loading }\end{array}$

2. When I get into a dispute with coworkers I dwell on $\quad .49 \quad .63$ the problem when I am at home.

3. I think about problems at work when I am on .45 vacation.

6. When someone at work criticizes me for something,

I dwell on it at home.

14. I discuss family problems with my boss.

17. An argument with my co-workers often ruins my whole day.

18. I spend part of the weekend planning for the next week's work.

21. I take my frustrations with my boss, home with me whether I want to or not.

22. I think about my co-workers while driving to work.

25. My friends and I frequently discuss work-related problems.

26. I have lost sleep worrying about work.

Note. A part-whole correlation partial is between each item and the remaining 9 items of the scale.

item SOS $(\underline{r}=.86)$. It might be noted that this version of the SOS did not include the marker item. At this time it was apparent that the SOS measured work-to-home spillover rather than "compartmentalization," since the marker item was believed to have been the exemplar of compartmentalization and was now removed.

Reliability. Coefficient alpha for the 10 -item SOS scale was .76, which is close to the alpha $(.80)$ for the 28 -item scale. A test-retest correlation of .80 was obtained when participants completed the SOS on occasions separated by an interval of 6 weeks. 
Convergent and Discriminant Validity. Table 5 lists intercorrelations among the scales as well as their alpha coefficients (on the diagonal). Scores on the SOS10, Small and Riley's (1990) three scales, Grzywacz and Marks' (2000) four measures of spillover, the five personality factors, and the five subscales of coping were subjected to principal components factor analysis followed by a varimax rotation. Six factors emerged that explained 59.7 percent of the variance (see Table 6). Only loadings over .40 are listed in the table. The six factors that emerged appeared to reflect general spillover, personality, coping, negative spillover, positive spillover, and stress reduction. Factor one included the variables of the Small and Riley's spillover scales and Grzywacz and Marks' negative work-to-home sub scale. Factor Two included the five BFI dimensions. Factor three included three of the coping subscales. Factor four included the SOS, two of Grzywacz and Marks sub-scales (negative work to home \& negative home to work), and one dimension of personality (neuroticism). Factor six included two sub-scales of coping (change situation \& symptom reduction). These findings are consistent with two of the study's original hypotheses. First, the SOS and spillover measures loaded on the same factors; second, the SOS and spillover measures loaded on different factors than the coping or BFI factors.

Steiger's (1980) method for testing the differences between correlations was modified to test the following statistical hypothesis: The correlation between the SOS and the average of the spillover scales is significantly higher than the correlation between the SOS and the average of the five personality measures or the 
average of the five coping measures. ${ }^{2}$ This modification indicated that the correlation between the SOS and spillover measures $(r=.44)$ was significantly higher than the correlation between the SOS and the personality measures $(\underline{r}=.29)$, $\mathrm{t}(310)=2.51, \mathfrak{p}<.01$. The correlation between the SOS and spillover measures was also significantly higher than the correlation between the SOS and the coping measures $(\underline{\mathrm{r}}=.15), \mathrm{t}(310)=4.63, \mathrm{p}<.01$.

Demographic Controls. In order to determine if the SOS differed on demographic variables, such as gender, a series of independent t-tests and one-way ANOVA's (for marital status, ethnicity, and age) were conducted. No significant differences were found between men and women on SOS scores $(\underline{M}=2.49$ vs. 2.51), $\underline{t}(310)=-.29$. Nor were significant differences found for ethnicity $\underline{F}(4,307)=2.05$, and the zero-order correlation between age and the SOS was also nonsignificant $(\underline{r}=$ $-.01)$. The age of the 58 participants with children $(\underline{\mathrm{M}}=31.17, \underline{\mathrm{SD}}=9.70)$ was significantly higher than those with no children $(\underline{\mathrm{M}}=23.53, \underline{\mathrm{SD}}=4.08), \underline{\mathrm{t}}(310)=$ $9.46, \mathrm{p}<.001$. However, no significant differences were found between the SOS and participants with children and those without when age was included as a covariate $\underline{t}$ $(310)=.20, \mathrm{~ns}$

2 Steiger's (1980) formula had to be modified to take into account the fact that the hypothesis referred to multiple measures rather than single measures of spillover, coping, and personality variables. This modification was accomplished by first regressing the six spillover sub-scales on the SOS, which yielded a multiple correlation of .463 . A multiple correlation of 288 was obtained when the five personality variables were regressed on SOS. Next, a canonical correlation analysis was performed to estimate the correlation between five personality variables and the six measures of spillover. The correlation for the first set of canonical variates equaled .341 . These values were then entered into Steiger's formula 10 to estimate the correlations between the SOS and spillover $(\underline{I}=.46)$, SOS and personality $(\underline{r}=.29)$, and spillover and personality $(\underline{r}=.34)$. Similar procedures were followed to assess the discriminant validity of spillover and coping measures. 
Parental status was examined by comparing participants with children to those without children; again no significant differences were found between the two groups $(\underline{M}=2.50$ vs. 2.56$), \underline{t}(310)=-.58$. There were also no significant differences between full time workers ( $>40$ hours) and part time workers $(<40$ hours $)(\underline{M}=$ 2.57 vs. 2.46$), \underline{t}(310)=1.36$. Job type was determined utilizing participant demographic information from the SOS survey and matching the given job description to classification codes used by the US Census Bureau (2003). The jobs were identified as either a professional (white collar) or industrial (blue collar) job. The category of white-collar jobs consisted of accountants, engineers, medical professionals, teachers, draftsmen, advertising agents, paralegals; blue collar jobs consisted of wait staff, cashiers, construction workers, receptionists, daycare workers, bank tellers, shipping and receiving clerks, and sales clerks. An independent $t$-test indicated that there was not a significant difference between blue collar workers $(\underline{\mathrm{M}}=2.57, \underline{\mathrm{SD}}=.84)$ and white collar workers $(\underline{\mathrm{M}}=2.47, \underline{\mathrm{SD}}=.67)$, $\mathrm{t}(310)=1.14$

Marital status was the only demographic that attained significance, $F(2,309)$ $=3.37, \underline{p}<.05$ when the scores for the three groups (i.e., never married, married or living together, previously married) were entered into an ANOVA. Bonferoni $\underline{t}$ tests indicated that never married participants scored significantly lower on the SOS $(\underline{M}=$ $24.07, \underline{S D}=7.02)$ than the married participants or living together $(\underline{\mathrm{M}}=26.49, \underline{\mathrm{SD}}=$ 7.14) and the previously married participants $(\underline{\mathrm{M}}=26.00, \underline{\mathrm{SD}}=6.80)$, and the latter groups did not differ. 
Table 5

Intercorrelations Between Scales and Demographic Variables

\begin{tabular}{|c|c|c|c|c|c|c|c|c|c|c|}
\hline Variable & 1 & 2 & 3 & 4 & 5 & 6 & 7 & 8 & & 9 \\
\hline 1. SOS & .76 & & & & & & & & & \\
\hline 2. Leisure & $.25^{* *}$ & .43 & & & & & & & & \\
\hline 3. Marital relations & $.25^{* *}$ & $.48^{* *}$ & .60 & & & & & & & \\
\hline 4. Home manage & $.25^{* *}$ & $.59 * *$ & $.40 * *$ & .63 & & & & & & \\
\hline 5. Neg. work-home & $.38^{* *}$ & $.36 * *$ & $.36 * *$ & $.41^{* *}$ & .77 & & & & & \\
\hline 6. Neg. home-work & $.20^{* *}$ & $.20 * *$ & $.30 * *$ & $.19 * *$ & $.37 * *$ & .60 & & & & \\
\hline 7. Pos. work-home & $.13 *$ & -.00 & .08 & -.03 & .06 & .02 & .63 & & & \\
\hline 8. Pos. home-work & $.16^{* *}$ & .01 & .08 & .07 & $.15^{* *}$ & .01 & $.35^{* *}$ & .65 & & \\
\hline 9. Change Situation & .02 & .07 & .07 & .02 & .08 & $.14^{*}$ & .06 & .0 & & .77 \\
\hline 10. Accommodation & -.08 & .03 & .03 & -.01 & -.06 & -.03 & -.01 & -.0 & & -.06 \\
\hline 11. Devaluation & -.06 & -.00 & .02 & -.02 & -.02 & .01 & .02 & -.0 & & .02 \\
\hline 12. Avoidance & $-.13^{*}$ & .10 & .03 & .01 & -.02 & .01 & -.05 & -.1 & & .01 \\
\hline 13. Symptom reduce & -.07 & -.01 & .02 & .01 & -.01 & -.06 & .10 & & & $.22 * *$ \\
\hline 14. Extraversion & .08 & .01 & -.05 & -.02 & .04 & .11 & .11 & .0 & & .09 \\
\hline 15. Agreeableness & .00 & -.05 & $-.14^{*}$ & -.09 & .00 & $-.12^{*}$ & -.02 & .20 & & -.10 \\
\hline 16. Conscientious & $.15^{* *}$ & -.07 & -.04 & -.04 & .07 & -.05 & $.14^{*}$ & .21 & & -.06 \\
\hline 17. Neuroticism & $.20 * *$ & $.12^{*}$ & $.15^{* *}$ & $.14^{*}$ & $.20 * *$ & $.17^{* *}$ & -.05 & -.0 & & .10 \\
\hline 18. Openness & .01 & -.07 & -.01 & -.04 & .08 & .06 & $.18^{* *}$ & & & .08 \\
\hline \multicolumn{11}{|l|}{ Table 5 (continued) } \\
\hline Variable & 10 & 11 & 12 & 13 & 14 & 15 & 16 & & 17 & 18 \\
\hline 10. Accommodate & .69 & & & & & & & & & \\
\hline 11. Devaluation & $.39 * *$ & .91 & & & & & & & & \\
\hline 12. Avoidance & $.26^{* *}$ & $.55^{* *}$ & .85 & & & & & & & \\
\hline 13. Symptom reduce & .09 & $.13^{*}$ & $.30 * *$ & .70 & & & & & & \\
\hline 14. Extraversion & -.07 & .00 & -.03 & .11 & .79 & & & & & \\
\hline 15. Agreeableness & $.17 * *$ & $.12^{*}$ & .02 & .10 & $.22^{* *}$ & .73 & & & & \\
\hline 16. Conscientious & -.00 & -.09 & $-.20 * *$ & -.01 & $.22^{* *}$ & $.36 * *$ & .63 & & & \\
\hline 17. Neuroticism & -.01 & -.01 & .06 & .04 & $-.22^{* *}$ & $-.30 * *$ & & & .77 & \\
\hline 18. Openness & -.05 & -.05 & .04 & $.16^{*}$ & $.31^{* *}$ & $.30 * *$ & & $e^{* *}$ & $-.21^{*}$ & $* \quad .78$ \\
\hline
\end{tabular}

Note. Coefficient alphas are presented in boldface along the diagonal. Leisure, marital relations, and home management are from Small and Riley (1990); negative work-tohome, negative home-to-work, positive work-to-home, and positive home-to-work are from Grzywacz and Marks (2000); change situation, accommodation, devaluation, avoidance and symptom reduction are from Edwards and Baglioni (1993); extraversion, agreeableness, conscientiousness, neuroticism, and openness are from John, Donahue, and Kantle (1991).

${ }^{*} \mathrm{p}<.05 .{ }^{* *} \mathrm{p}<.01$. 
Table 6

Factor Loadings from Principal-Components Analysis: Eighenvalues, and Percentages of Variance.

\begin{tabular}{|c|c|c|c|c|c|c|}
\hline \multirow[b]{2}{*}{ Scale } & \multicolumn{6}{|c|}{ Factor Loading } \\
\hline & $\begin{array}{l}\text { General } \\
\text { spillover }\end{array}$ & BFI & Coping & $\begin{array}{l}\text { Negative } \\
\text { spillover }\end{array}$ & $\begin{array}{l}\text { Positive } \\
\text { spillover }\end{array}$ & $\begin{array}{l}\text { Stress } \\
\text { reduce }\end{array}$ \\
\hline SOS & & & & .57 & & \\
\hline Marital relations & .66 & & & & & \\
\hline Leisure & .85 & & & & & \\
\hline Home management & .83 & & & & & \\
\hline Negative work-home & .47 & & & .58 & & \\
\hline Positive work-home & & & & & .74 & \\
\hline Negative home-work & & & & .75 & & \\
\hline Positive home-work & & & & & .77 & \\
\hline Change situation & & & & & & .70 \\
\hline Accommodation & & & .70 & & & \\
\hline Devaluation & & & .83 & & & \\
\hline Avoidance & & & .75 & & & \\
\hline Symptom reduction & & & & & & .64 \\
\hline Extraversion & & .66 & & & & \\
\hline Agreeableness & & .69 & & & & \\
\hline Conscientious & & .59 & & & & \\
\hline Neuroticism & & -.57 & & .44 & & \\
\hline Openness & & .65 & & & & \\
\hline Eigenvalues & 2.85 & 2.34 & 1.98 & 1.36 & 1.18 & 1.03 \\
\hline$\%$ of Variance & 15.83 & 13.02 & 11.01 & 7.56 & 6.54 & 5.76 \\
\hline
\end{tabular}

Note. Leisure, marital relations, and home management are from Small and (1990); negative work-to-home, negative home-to-work, positive work-to-home, and positive home-to-work are from Grzywacz and Marks (2000); change situation, accommodation, devaluation, avoidance and symptom reduction are from Edwards and Baglioni (1993); extraversion, agreeableness, conscientiousness, neuroticism, and openness are from John, Donahue, and Kantle (1991). Only loadings over .40 are listed. 
Predictive Validity. As expected, the SOS was correlated with

demoralization, $(\underline{r}=.27), \underline{p}<.001$. From the regression coefficients in Table 7 , it can be seen that the same correlation was obtained, partial $\underline{\underline{r}}=.27$, when the SOS was entered after demographic variables in a hierarchical regression analysis. The correlation was little altered, partial $\underline{\mathrm{r}}-.20$, when its entry followed demographic variables and other measures of spillover on the second step in the analysis. Nearly the same correlation was obtained, partial $\underline{r}=.19$, when the prediction equation included personality as well as demographic and spillover measures. Finally, the SOS also attained significance, partial $\underline{\underline{r}}=.20$, in analyses that controlled for all of the other personality, spillover, and coping measures.

\section{Measurement Models}

Confirmatory Factor Analyses of SOS 10. The program AMOS (Arbuckle \& Wothke, 1999) was employed to perform a confirmatory factor analysis on the 10 items that comprised the short version of the SOS. Table 8 presents original and standardized factor loadings that were obtained when it was assumed that the items loaded on a single factor. It might be noted that the loadings are similar to the ones from the exploratory factor analysis, which were listed in Table 4, and all of the estimated (i.e., free) coefficients were highly significant.

Turning to the model's overall fit, there is unfortunately very little consensus about the best index for assessing model adequacy (Bollen, 1989; Kline, 1998). Kline recommended that investigators report chi-square, the standardized root mean square residual (SRMR), and Bentler and Bonett's (1980) normed fit index (NFI), 
Summary of Hierarchical Multiple Regression Analysis: SOS and Spillover Scales With Demoralization as Criterion

\begin{tabular}{lccc}
\hline Predictor & $\mathrm{B}$ & $\boldsymbol{\beta}$ & $\Delta \mathrm{R}^{2}$ \\
\hline Step 1. Demographics & & & \\
Gender & .09 & $.12^{*}$ & \\
Age & -.05 & -.10 & \\
Parental status & .13 & $.15^{*}$ & \\
Employment status & .03 & .05 & \\
Married & -.11 & $-.13^{*}$ & \\
Divorced or separated & .03 & .00 & \\
SOS & .13 & $.27^{* * *}$ & .072
\end{tabular}

Step 2. Controlling for other spillover measures

Gender

Age

Parental status

Employment status

Married

Divorced or separated

SOS

Marital relations

Leisure

Home management

Negative work-to-family spillover

Positive work-to-family spillover

Negative family-to-work spillover

Positive family-to-work spillover

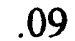

$-.05$

.08

.03

$-.07$

.09

.09

.04

$-.02$

$-.02$

.09

.01

.09

$-.09$
$.12^{*}$

$-.09$

.10

.04

$-.08$

.01

$.20^{* *}$

.07

$-.04$

$-.05$

$.19 * *$

.03

$.16^{* *}$

$-.20$

.103

Step 3. Controlling for other spillover \& personality

Gender

Age

Parental status

Employment status

Married

Divorced or separated

SOS

Marital relations

Leisure

Home management

Negative work-to-family spillover

Positive work-to-family spillover

Negative family-to-work spillover

Positive family-to-work spillover
.05

$-.04$

.05

.02

$-.04$

.01

.09

.02

$-.01$

$-.03$

.08

.02

.07

$-.08$
.07

$-.07$

.06

.03

$-.05$

.01 $.19 * *$

.04

$-.03$

$-.06$ $.16^{* *}$ .03 
Table 7 (continued)

\begin{tabular}{lccc}
\hline Predictor & $\mathrm{B}$ & $\boldsymbol{\beta}$ & $\Delta \mathrm{R}^{2}$ \\
\hline Extraversion & -.01 & -.03 & \\
Agreeableness & -.02 & -.03 & \\
Conscientiousness & -.07 & $-.12^{*}$ & \\
Neuroticism & .11 & $.26^{* * *}$ & \\
Openness & .07 & $.14^{*}$ & .084
\end{tabular}

Step 4. Controlling for spillover, personality \& coping

Gender

Age

Parental status

Employment status

Married

Divorced or separated

SOS

Marital relations

Leisure

Home management

Negative work-to-family spillover

Positive work-to-family spillover

Negative family-to-work spillover

Positive family-to-work spillover

Extraversion

Agreeableness

Conscientiousness

Neuroticism

Openness

Change situation

Accommodation

Devaluation

Avoidance

Symptom reduction

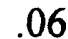

$-.03$

.03

.01

$-.01$

.03

.10

.02

$-.09$

$-.03$

.08

.10

.08

$-.08$

$-.01$

$-.04$

$-.07$

.11

.08

$-.02$

.05

.03

$-.10$

.04
.08

$-.06$

.04

.02

$-.02$

.00

$.20 * * *$

.03

$-.02$

$-.07$

$.17 * *$

.02

$.14^{*}$

$-.19 * *$

$-.03$

$-.08$

$-.12 *$

$.25^{* * *}$

$.15^{*}$

$-.05$

$14 *$

.01

$-.03$

.028

Note. $\mathrm{R}^{2}=.332, \underline{\mathrm{F}}(24,287)=5.95, \mathrm{p}<.001$. Leisure, marital relations, and home management are from Small and Riley (1990); negative work-to-home, negative home-to-work, positive work-to-home, and positive home-to-work are from Grzywacz and Marks (2000); change situation, accommodation, devaluation, avoidance and symptom reduction are from Edwards and Baglioni (1993); extraversion, agreeableness, conscientiousness, neuroticism, and openness are from John, Donahue, and Kantle (1991). Marital status was dummy coded into two categories: (1) Married and (2) divorced or separated and never married.

${ }^{*} \mathrm{p}<.05 .^{* *} \mathrm{p}<.01 .^{* * *} \mathrm{p}<.001$ 
Table 8

Original Standardized Factor Loadings for SOS10 Scale

\begin{tabular}{ccccc}
\hline Item & Lambda $(\lambda)$ & $Z$ & Standardized $\lambda$ & $\begin{array}{c}\text { EFA } \\
\text { Loadings }\end{array}$ \\
\hline 1 & 1.00 & & 0.58 & 0.63 \\
2 & 0.92 & 6.13 & 0.54 & 0.59 \\
3 & 0.67 & 5.39 & 0.39 & 0.45 \\
4 & 0.55 & 4.81 & 0.34 & 0.61 \\
5 & 0.85 & 6.78 & 0.52 & 0.41 \\
6 & 0.65 & 4.91 & 0.35 & 0.58 \\
7 & 0.82 & 6.48 & 0.49 & 0.58 \\
8 & 0.64 & 5.32 & 0.38 & 0.46 \\
9 & 0.73 & 5.95 & 0.44 & 0.71 \\
10 & 0.98 & 7.39 & 0.59 & 0.55 \\
\hline
\end{tabular}

Note. EFA $=$ exploratory factor analysis

which is sometimes termed Bollen's $\rho_{1}$. Many lists of recommended indices also include Bentler's (1990) non-normed fit index (NNFI), which Bollen terms $\rho_{2}$. Given the fact that the factor loadings are based on a fairly large sample size $(\mathrm{N}=312)$, it is perhaps not surprising the model's observed chi-square attained significance, $\chi^{2}(35)$ $=60.51, \mathrm{p}<.005$; however, it might noted that several authors suggest that models with significant chi-square values can be regarded as having a reasonable fit when the ratio $\chi^{2}$ to degrees of freedom (df) is less than 2.0. This model's $\chi^{2} / \mathrm{df}$ ratio is 1.73. The model's SRMR is .048 , which is considerably less than the cutoff $(.10)$ that Kline proposed as an upper limit. The model's NFI and NNFI indices are .86 and .91, respectively. The NFI is less than the value (namely, .90) that Bentler and Bonnett recommended as a lower limit for adequate fit. However, an inspection of modification indices revealed that the model's fit could be improved substantially by estimating the correlation between the second and ninth items' residuals. Doing so 
reduced the model's test statistic to a nonsignificant $\chi^{2}(34)=44.23, \mathrm{p}>.10$, and brought its NFI up to 0.90 .

Work-Home Spillover. Similar procedures were followed to evaluate items from Grzywacz and Marks' (2000) Work-Home Spillover Scale. As previously described, Grzywacz and Marks developed their scale to measure four types of spillover: negative work-to-home, positive work-to-home, negative home-to-work, and positive home-to-work. Figure 1 presents factor loadings and correlations (sometimes termed phi coefficients) between the factors that Grzywacz and Marks proposed (see also Tables 9 and 10). The phi coefficients in Table 10 indicate that negative work-to-home spillover was correlated with home-to-work spillover and positive home-to-work spillover, and the latter was correlated with positive work-tohome spillover. Interestingly, there does not appear to be any relationship for amount of spillover, as evidenced by the nonsignificant correlations between positive and negative work-to-home and home-to-work $(\underline{r}=.07)$ and home-to-work $(\underline{r}=-.03)$.

The Table 9 indicates that the scales did in fact load on each of the proposed factors. However, it should be cautioned that the model's fit indices failed to achieve levels that are typically described as adequate, as evidenced by a highly significant chi-square, $\chi^{2}(\mathrm{df}=99)=240.44, \underline{p}<.001$, and a $\chi^{2} / \mathrm{df}$ ratio that exceeded $2.0($ see Figure 2). In addition, the model had a NFI index of .78, which is considerably less than the .90 figure that Bentler and Bonnett (1980) proposed as adequate.

Multidimensional Measure of Work Spillover. Small and Riley (1990) originally attempted to assess trait and method variance from peer and self-report 
Figure 1. Confirmatory Factor Analysis of the Work-Home Spillover Scale

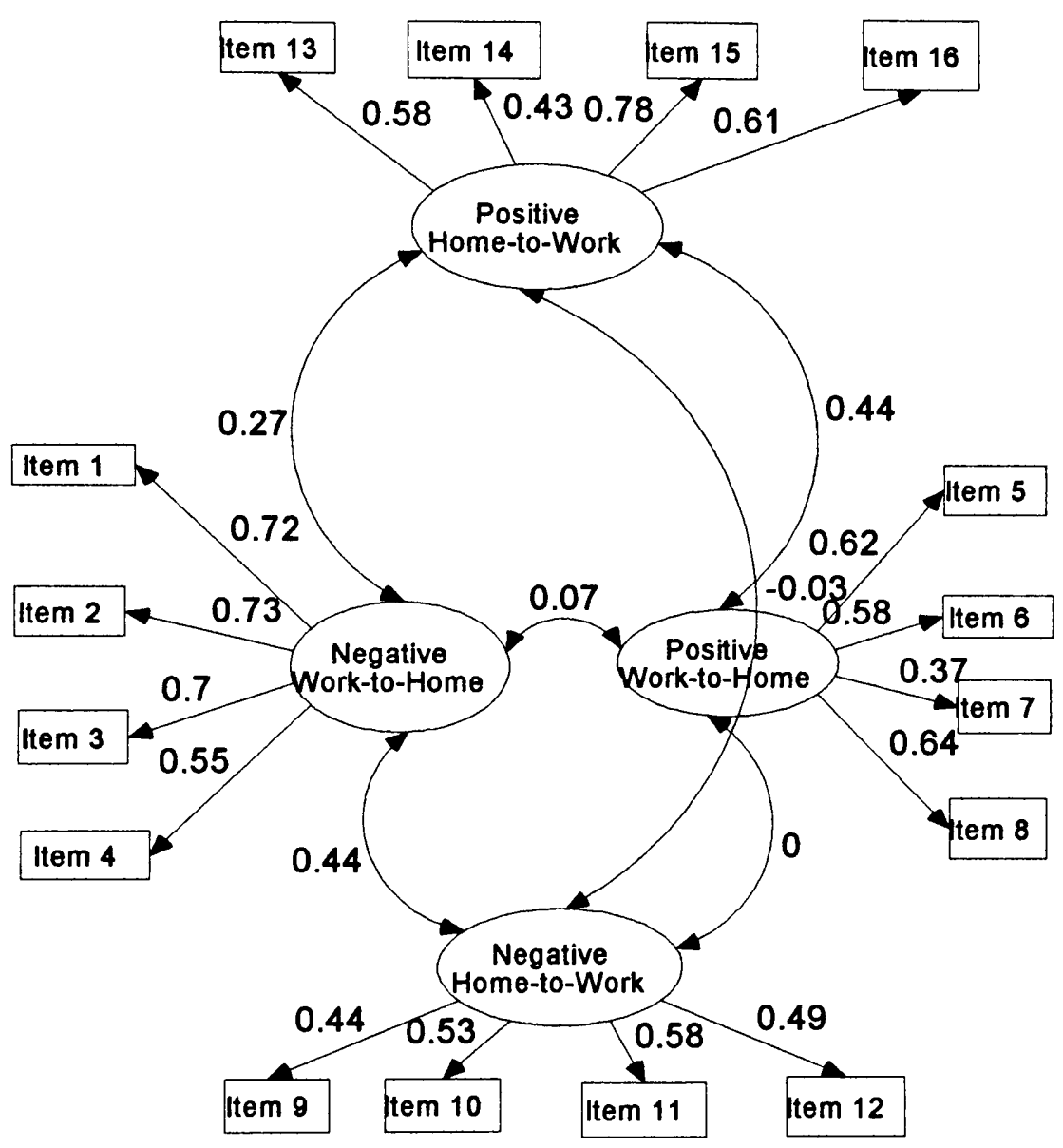

Standardized Regression Coefficients for Grzywacz and Marks (2000) Spillover Scale

Chi-square $(99)=240.44, \mathrm{p}<.001$, Chi-square $/ \mathrm{df}=2.43$

$\mathrm{NFI}=.78, \mathrm{NNFI}=.82$, Standardized root mean square residuals $=.07$

Note. Error terms are omitted for purposes of presentation. 
Table 9

Factor Loadings (Validities) for Items on Grzywacz and Marks' (2000) Work-Home Spillover Scale

\begin{tabular}{|c|c|c|c|c|c|c|c|c|}
\hline \multirow[b]{3}{*}{ Item } & \multicolumn{4}{|c|}{ Work-to-Home } & \multirow{2}{*}{\multicolumn{2}{|c|}{ Negative }} & \multirow{2}{*}{\multicolumn{2}{|c|}{$\begin{array}{c}\text { Home-to-Work } \\
\text { Positive }\end{array}$}} \\
\hline & \multicolumn{2}{|c|}{ Negative } & \multicolumn{2}{|c|}{ Positive } & & & & \\
\hline & $\begin{array}{c}\text { Lambda } \\
(\lambda)\end{array}$ & Z & $\begin{array}{c}\text { Lambda } \\
(\lambda)\end{array}$ & Z & $\begin{array}{c}\text { Lambda } \\
(\lambda)\end{array}$ & Lambda & $\begin{array}{c}\text { Lambda } \\
(\lambda)\end{array}$ & Z \\
\hline 1 & 1.44 & 8.41 & & & & & & \\
\hline 2 & 1.21 & 8.35 & & & & & & \\
\hline 3 & 1.30 & 8.48 & & & & & & \\
\hline 4 & 1.00 & & & & & & & \\
\hline 5 & & & 1.00 & & & & & \\
\hline 6 & & & 0.91 & 6.62 & & & & \\
\hline 7 & & & 0.57 & 4.85 & & & & \\
\hline 8 & & & 1.09 & 6.81 & & & & \\
\hline 9 & & & & & 0.91 & 4.87 & & \\
\hline 10 & & & & & 1.16 & 5.32 & & \\
\hline 11 & & & & & 1.55 & 5.49 & & \\
\hline 12 & & & & & 1.00 & & & \\
\hline 13 & & & & & & & 1.00 & \\
\hline 14 & & & & & & & 0.77 & 5.82 \\
\hline 15 & & & & & & & 1.38 & 8.15 \\
\hline 16 & & & & & & & 0.92 & 7.62 \\
\hline
\end{tabular}

Table 10

Intercorrelations Among Factors for Types of Spillover on Grzywacz and Marks' (2000)

\begin{tabular}{lcccc}
\hline & & 2. WH+ & 3. HW+ & 4. HW- \\
\hline 1. Negative Work-to-Home (WH-) & .07 & $.27^{*}$ & $.44^{*}$ \\
2. Positive Work-to-Home (WH+) & & $.44^{*}$ & .00 \\
3. Negative Home-to-Work (HW-) & & & -.03 \\
4. Positive Home-to-Work (HW+) & & & \\
${ }^{*} \mathrm{p}<.05$. & & &
\end{tabular}


versions on their multidimensional measure of Work Spillover. Only the self-report version of their instrument was used here. However, their scale was originally constructed so that its 15 items assessed how four processes (time, energy, psychological interference, and general) and three roles (marital relationships, leisure activities, and home management) might be affected by work spillover. Because each item was designed to be sensitive to both role and process variables, it was possible to develop what might be termed a multi-role multi-process model to examine correlations among the 15 scale items. The model in Figure 2 was used to estimate correlations among the three role factors and the four process variables. As is typically the case with such matrices (Schmitt \& Stults, 1986), it was assumed that role and process factors are uncorrelated.

Table 11 presents factor loadings for the three role and four process factors that are supposed to describe work spillover on Small and Riley's (1990) scale. Diagnostic tests provided a mixed picture for the model's fit. On the one hand, the model's chi-square was significant, $\chi^{2}(66)=155.03$, and the $\chi^{2} / \mathrm{df}$ ratio of 2.25 , is higher than the 2.0 that is usually described as adequate. On the other hand, the model's NFI equaled .90 , as did its NNFI, and its standardized root mean square of .06 is less than the value $(.10)$ that is usually described as adequate. 
Figure 2. Multi-Role Multi-Process Model for Multidimensional Scale of Spillover

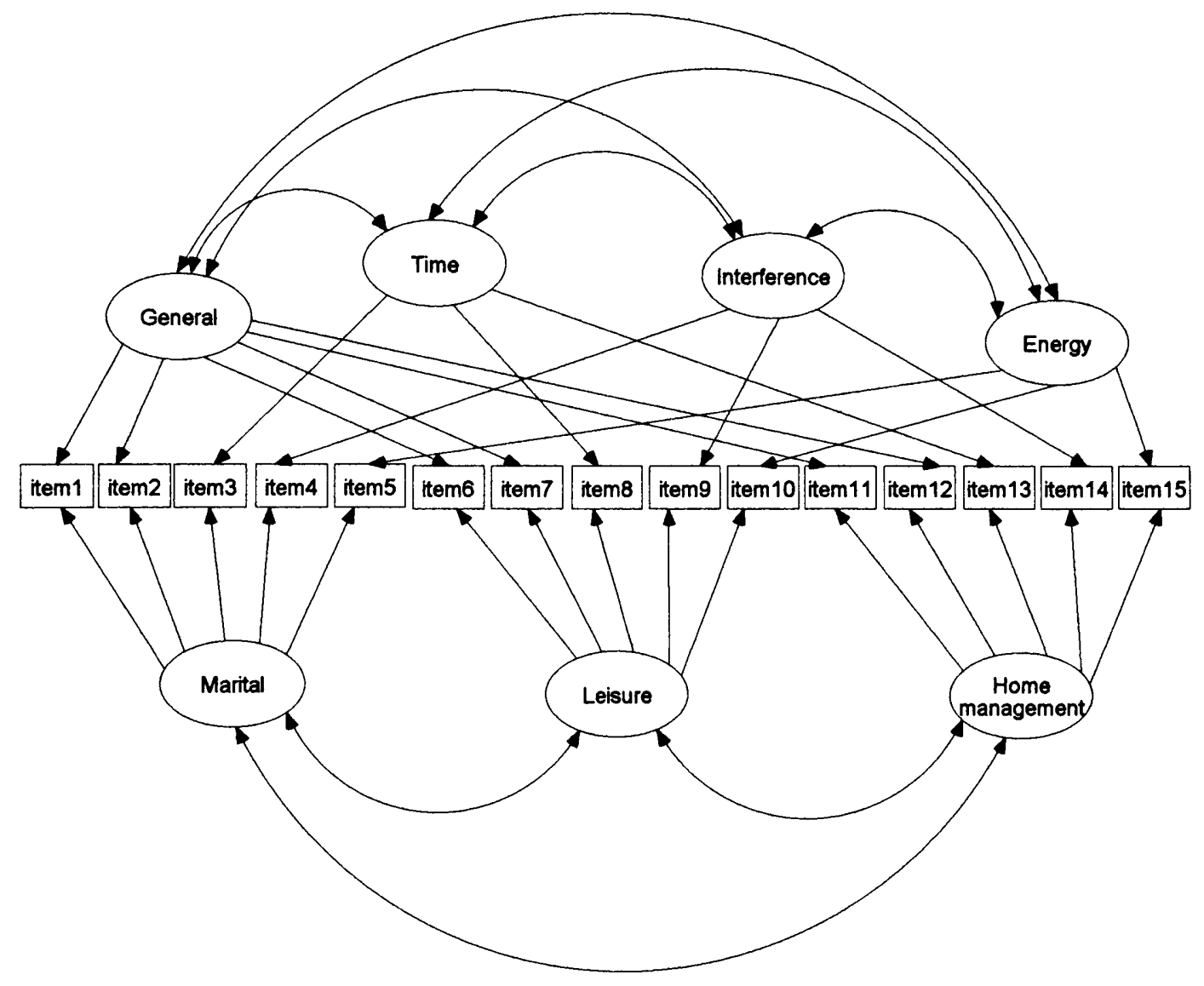

Note. Error terms are omitted for purposes of presentation. 


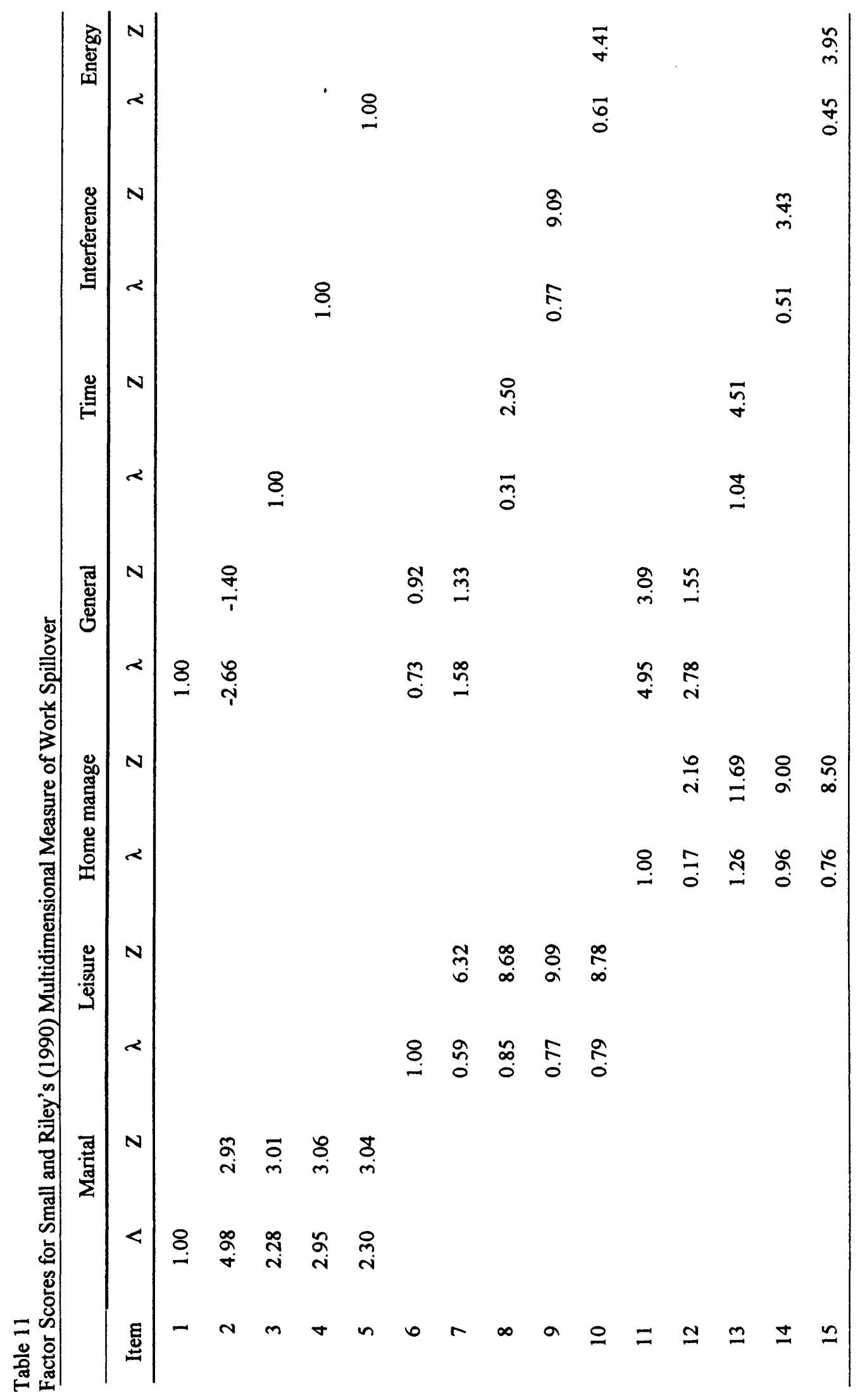




\section{DISCUSSION}

This study was designed to develop a psychometrically valid measure of compartmentalization that could be used in subsequent research on work-home spillover. Unfortunately, a factor analysis indicated that none of the items in the original questionnaire pool loaded on the same factor as the marker item (i.e., "I try to keep my life at home and at work separate and apart from each other"), which was regarded as prototypical of compartmentalization. It is worth noting that Sumer and Knight (2001) recently reported results using a two-item measure of compartmentalization that had an alpha coefficient of .72 . Therefore, it may be possible to develop a more reliable and valid measure of compartmentalization by combining the marker item from this study with the two-item measure from Sumer and Kinghts investigation.

Although this study's original goal was not realized, it was successful in developing a short and psychometrically valid measure of negative work-to-home spillover that may be useful in future research. The factorial validity of the SOS scale was supported by analyses that indicated that its 10 items loaded on a single factor. The scale's convergent validity was verified by results from a principle components factor analysis that demonstrated that the SOS scale loaded on the same factor as Grzwacz and Marks (2000) negative work-to-home and negative home-towork scales. Evidence for discriminant validity was provided by very low correlations with four out of the five BFI sub-scales, and all five of the coping subscales. In addition, evidence of convergent and discriminant validity were provided 
by structural equation models that indicate that the correlation between the SOS and spillover scales are significantly higher than the correlation between the SOS and either personality or coping measures. Finally, the predictive validity of the SOS was demonstrated by results from a hierarchical regression analysis of demoralization. The SOS accounted for a significant proportion of the variance when its contribution was evaluated after demographic variables, personality measures, coping scales, and existing instruments for assessing spillover.

Previous research has suggested that both work-to-home and home-to-work spillover should be measured independently of one another (Grzywacz \& Marks, 2000; Netemeyer, Boles, \& McMurrian, 1996). However, more recent studies have shifted the focus away from directionality and placed more emphasis on the positive and negative forms of spillover (Grzywacz, Almeida, \& McDonald, 2002). This shift in focus may be attributed to results from studies (Barnett, 1994; Bolger, DeLongis, Kessler, \& Wethington, 1989; Williams \& Alliger, 1994), which indicate that spillover is the dissemination of stress and attitudes from one domain to another. Because the SOS is a measure of negative spillover, there is a need to develop a short scale for assessing spillover's positive consequences. Doing so would allow researchers to investigate the dissemination of stress with two relatively short measures.

The results obtained here are open to possible criticism that they were based solely on correlations among self-report instruments. This criticism could be addressed in future studies by comparing self-report levels of spillover with ratings 
made by, for example, friends, spouses, and coworkers (Small \& Riley, 1990). It should also be cautioned that this study's results are based on measures obtained at a single point in time; longitudinal research is needed to determine if scores on the SOS predict future levels of stress. Research is also needed that employs a less direct measure of spillover since asking employees if they are bothered by work-home spillover introduces social desirability as a rival hypothesis (Robinson, et. al., 1991). A better strategy would be to obtain separate measures of stress and strain in each domain (i.e., work stress and home strain and, vice versa, home stress and work strain). Post measures of spillover such as the one used here call into question the actual definition of spillover. Previous researchers (Bolger et. al., 1989) have measured spillover while the participant is actually at work or home, while other studies, including this one have used an indirect approach (Grzywacz \& Marks, 2000; Small \& Riley, 1990). Future research should examine if these scales are actually measuring "carry over effects" from one place (e.g., work) at one time to another place (e.g., home) at a latter time.

Some of the demographic variables observed in this study should be further explored to see if there are any additional explanations for variances on the SOS score. Such items could include whether or not a participant is a part time or full time student and, if they are a parent, what are the ages of their children. Items such as the aforementioned could have an impact on an individual's total SOS score and should be explored further. In addition, it could be argued that discriminant validity should have been assessed by examining correlations between individual dimensions 
on the BFI and SOS. By limiting the BFI to an overall scale score separate dimensions of the BFI relating to the SOS could have been overlooked which led to incorrect assumptions from a divergent validity perspective. Future studies comparing the BFI to the SOS should do so by comparing the 5 dimensions separately to avoid this problem.

Finally, it is not unusual to question the external validity of studies that employ undergraduates as subjects (Barr \& Hitt, 1986; Rind, Tromovitch \& Bauserman, 1998; Rosenthal \& Rosnow, 1986). However, although this study capitalized on the ready availability of student populations, an attempt was made to obtain results that could be generalized to the working population by restricting the study's sample to students who were currently employed. It might be objected that the sample contained a disproportionate number of young employees. However, it can be argued that this limit to external validity is less serious than the common practice of relying on data from workers in a single corporation or industry. Despite the previously listed limitations, this study's findings should advance the literature by introducing a measure that is more reliable and valid than existing measures of spillover. 


\section{References}

Adorno, T. W., Frenkel-Brunswik, E., Levinson, D., \& Sanford, R. N. (1950). The authoritarian personality. New York: Harper.

Ahrentzen, S. (1989). A place of peace, prospect, and a P. C.: The home as office. Journal of Architecture and Planning Research, 6, 271-288.

Ahrentzen, S. B. (1990). Managing conflict by managing boundaries: How professional homeworkers cope with multiple roles at home. Environment and Behavior, 22, 723-752.

Allport, G. W. \& Odbert, H. S. (1936). Approach, avoidance, and coping with stress. Psychological Monographs, 47, 171.

Arbuckle, J. L., \& Wothke, W. (1999). Amos 4.0 user's guide. Chicago, IL: SmallWaters.

Barling, J., \& Rosenbaum, A. (1986). Work stressors and wife abuse. Journal of Applied Psychology, 71, 346-348.

Barnett, R. C. (1994). Home-to-work spillover revisited: A study of full-time employed women in dual-earner careers. Journal of Marriage and the Family, 56, 647-656.

Barnett, R. C., \& Hyde, J. S. (2001). Women, men, work, and family: An expansionist theory. American Psychologist, 56, 781-796.

Barr, S. H., \& Hitt, M. A. (1986). A comparison of selection decision models in manager versus student samples. Personnel Psychologist, 39, 599-617.

Belsky, J., Perry-Jenkins, M., \& Crouter, A. C. (1985). The work-family interface and marital change across the transition to parenthood. Journal of Family Issues, 6, 205-220.

Bentler, P. M. (1990). Comparative fit indexes in structural models. Psychological Bulletin, 107, 238-246.

Bentler, P. M., \& Bonett, D. G. (1980). Significance tests and goodness of fit in the analysis of covariance structures. Psychological Bulletin, 88, 588-606.

Bolger, N., DeLongis, A., Kessler, R. C., \& Wethington, E. (1989). The contagion of stress across multiple roles. Journal of Marriage and the Family, 51, 175183. 
Bollen, K. A. (1989). Structural equations with latent variables. New York: Wiley.

Bromet, E. J., Dew, M. A., \& Parkinson, D. K. (1990). Spillover between work and family: a study of blue-collar working wives. In: Eckenrode J., \& Gore, S. (Eds.). Stress between work and family. New York: Plenum Press, 133-152. Campbell, A., Converse, P., \& Rodger, S. W. (1976). The quality of American life. New York: Sage.

Chan, C. J. \& Margolin, G. (1994). The relationship between dual-earner couples' daily work mood and home affect. Journal of Social and Personal Relationships, 11, 573-586.

Cooke, R. A., \& Rousseau, D. M. (1984). Stress and strain from family roles and Work role expectations. Journal of Applied Psychology, 69, 252-260.

Crouter, A. C. (1984). Spillover from family to work: The neglected side of the work-family interface. Human Relations, 37, 425-442.

Dohrenwend, B. P., Dohrenwend, B. S., Fabrikant, J. I., Kasl, S. V., Warheit, G. J., Bartlett, G. S., Chisholm, R. F., Goldsteen, R. L., Goldsteen, K., \& Martin, J. $\mathrm{L}$. (1979). Report of the president's commission on the accident at three mile island. U. S. Government Printing Office: Washington, DC.

Dohrenwend, B. P., Dohrenwend, B. S., Oksenberg, L., Cook, D., \& Shrout, P. E. (1974). What brief psychiatric screening scales measure. In B. S.

Dohrenwend \& B. P. Dohrenwend (Eds.), Conference on stressful life events: Their nature and effects (pp. 188-198). New York: Wiley.

Eckenrode, J., \& Gore, S. (1990). Stress and coping at the boundary of work and family. In J. Eckenrode \& S. Gore (Eds.) (pp. 1-16). New York: Plenum.

Edwards, J. R. (1992). The cybernetic theory of stress, coping, and well-being in organizations. Academy of Management Review, 17, 238-274.

Edwards, J. R., \& Baglioni, A. J. (1993). The measurement of coping with stress: Construct validity of the ways of coping checklist and the cybernetic coping scale. Work \& Stress, 7, 17-31.

Evans, G. W., Jacobs, S. V., Dooley, D., \& Catalono, R. (1987). The interaction of stressful life events and chronic strains on community mental health. American Journal of Community Psychology, 15, 23-24. 
Farmanfarmaian, R. (1989, November). Worksteading: The new frontier. Psychology Today, 23, 37-38, 42-44.

Frankenhaeuser, M. (1980). Psychoendocrine approaches to the study of stressful person-environment transactions. In H. Selye (Ed.) (Vol. 1, pp. 46-70). New York: Van Nostrand.

Geller, P. A., \& Hobfoll, S. E. (1994). Gender differences in job stress, tedium and social support in the workplace. Journal of Social and Personal Relationships, 11, 555-572.

Goffman, E. (1959). The presentation of self in everyday life. Garden City, NJ: Doubleday.

Greenberg, L., Moore, S., \& Greenberg, E. S. (1998). Work stress and problem alcohol behavior: A test of the spillover model. Journal of Organizational Behavior, 19(5), 487-502.

Grzywacz, J. G. (2000). Work-family spillover and health during midlife: Is managing conflict everything? American Journal of Health Prevention, 14, 238-243.

Grzywacz, J. G., Almeida, D. A., \& McDonald, D. A. (2002). Work-family spillover and daily reports of work and family stress in the adult labor force. Family Relations, 51, 28-36.

Grzywacz, J. G., \& Marks, N. F. (2000). Reconceptualizing the work-family interface: An ecological perspective on the correlates of positive and negative spillover between work and family. Journal of Occupational Health Psychology, 5, 111-126.

Hartig, T., Kylin, C., \& Johansson, G. (in press). Work without boundaries: Change in the social ecology of stress and restoration. Journal of Social Issues, 45 , 109-114.

John, O. P., Donahue, E. M., \& Kantle, R. (1991). The big five inventory-version $4 a$ and 54. Technical report, Institute of personality and social psychology, University of California, Berkeley, CA 94720.

John, O. P., \& Srivastava, S. (1999). Handbook of personality: theory and research. NewYork: Guilford Press.

Judy, R. W., \& D'Amico, C. (1999). Workforce 2020: Work and Workers in the $21^{\text {st }}$ century. Indianapolis, IN: Hudson Institute. 
Jöreskog, K., \& Sorbom, D. (1988). LISREL 7: A guide to the program and applications. Chicago: SPSS.

Kabanoff, B. (1980). Work and nonwork: A review of models, methods, and findings. Psychological Bulletin, 88, 60-77.

Kirchmeyer, C. (1992). Perceptions of nonwork-to-work spillover: Challenging the common view of conflict-ridden domain relationships. Basic and Applied Social Psychology, 13, 231-249.

Kline, R. B. (1998). Structural equation modeling. New York: Guilford.

Lambert, S. J. (1990). Processes linking work and family: A critical review and research agenda. Human Relations, 43, 239-257.

Larson, R. W., Richard, M. H., \& Perry-Jenkins, M. (1994). Divergent worlds: The daily emotional experience of mothers and fathers in the domestic and public spheres. Journal of Personality and Social Psychology, 67, 1034-1046.

Leiter, M. P., \& Durup, M. J. (1996). Work, home, and in-between: A longitudinal study of spillover. Journal of Applied Behavioral Science, 32, 29-47.

Marco, C. A., \& Suls, J. (1993). Daily stress and the trajectory of mood: Spillover, response assimilation, contrast, and chronic negative affectivity. Journal of Personality and Social Psychology, 64, 1053-1063.

Margolin, G., Christensen, A., \& John, R. S. (1996). The continuance and spillover of everyday tension in distressed and distressed families. Journal of Family Psychology, 10, 304-323.

Netemeyer, R. G., Boles, J. S., \& McMurrian, R. (1996). Development and validation of work-family conflict and family-work conflict scales. Journal of Applied Psychology, 81, 400-410.

Nunnally, J. C., \& Bernstein, I. H. (1994). Psychometric Theory. NY: McGraw-Hill.

Piotrkowski, C. S. (1979). Work and the family system. New York: The Free Press.

Piotrkowki, C. S., \& Repetti, R. L. (1984). Dual-earner families. Marriage and Family Review, 7, 99-124.

Pleck, J. H. (1977). The work-family role system. Social Problems, 24, 417-427. 
Rind, B., Tromovitch, P., \& Bauserman, R. (1998). A meta-analytic examination of assumed properties of child sexual abuse using college samples.

Psychological Bulletin, 124, 22-53.

Robinson, J. P., Shaver, P. R., \& Wrightsman, L. S. (1991). Measures of personality and social psychological attitudes. San Diego, CA: Academic Press.

Rosenthal, R., \& Rosnow, R. L. The volunteer subject. In R. Rosenthal \& R. L. Rosenthal (Eds.), Artifact in behavioral research, (p. 110). New York: Academic Press.

Roth, S., \& Cohen, L. J. (1986). Approach, avoidance, and coping with stress. American Psychologist, 41, 813-819.

Rousseau, D. M. (1978). Relationship of work to nonwork. Journal of Applied Psychology, 63, 513-517.

Sarbin, T. B., \& Allen, V. L. (1968). Role theory. In G. Lindzey \& E. Aronson (Eds.), The handbook of social psychology (2nd ed., Vol. 1, pp. 488-567). Reading, MA: Addison-Wesley.

Schmitt, N., \& Stults, D. M. (1986). Methodology review: Analysis of multitraitmultimethod matrices. Applied Psychological Measurement, 10, 1-22.

Showers, C. J., \& Kling, K. C. (1996). Organization of self-knowledge: Implications for recovery from sad mood. Journal of Personality and Social Psychology, $70,578-590$.

Showers, C. J., \& Ryff, C. D. (1996). Self-differentiation and well-being in a life transition. Personality and Social Psychology Bulletin, 22, 448-460.

Small, S. A., \& Riley, D. (1990). Toward a multidimensional assessment of work spillover into family life. Journal of Marriage and the Family, 52, 51-61.

Spence, J. T., \& Robbins, A. S. (1992). Workaholism: Definition, measurement, and preliminary results. Journal of Personality Assessment, 58, 160-178.

Staines, G. J. (1980). Spillover versus compensation: A review of the literature on the relationship between work and home. Human Relations, 33, 111-129.

Steiger, J. H. (1980). Tests for comparing elements of a correlation matrix. Psychological Bulletin, 87, 245-251. 
Sumer, H. C., \& Knight, P. A. (2001). How do people with different attachment styles balance work and family? A personality perspective on work-family linkage. Journal of Applied Psychology, 86, 653-663.

Turner, R. H. (1978). The role and the person. American Journal of Sociology, 84, $1-23$.

The US Census Bureau, (n.d.). The 2002 economic census. Retrieved January 2, 2003, from http://www.census.gov/epcd/www/econ97.html

Yuan, K.H. \& Bentler, P.M. (1994) Bootstrap-corrected ADF test statistics in covariance structure analysis. British Journal of Mathematical and Statistical Psychology, 47, 63-84.

Weiss, R. S. (1990). Bringing work stress home. In J. Eckenrode \& S. Gore (Eds.), Bringing work stress home (pp. 17-37). New York: Plenum Press.

Williams, K. S., \& Alliger, G., M. (1994). Role stressors, mood spillover, and perceptions of work-family conflict in employed parents. Academy of Management Journal, 37, 837-868. 